\title{
Performance Analysis of Low noise amplifier using Combline Bandpass Filter for X Band Applications
}

\author{
Mohammed Lahsaini ${ }^{1}$, Islam Toulali ${ }^{2}$, Lahbib Zenkouar ${ }^{3}$ \\ ${ }^{1}$ Materials and Instrumentation Group, LASMAR, Faculty of Science, Moulay Ismail University, Meknes, Morocco \\ ${ }^{2,3}$ Equipe de Recherche en Smart Communications (ERSC), E3S Research Center, Mohammadia School of Engineers \\ (EMI), Mohammed Vth University, Rabat, Morocco
}

\begin{tabular}{|c|c|}
\hline Article Info & ABSTRACT \\
\hline Article history: & This paper describes a procedure for designing broadband low noise \\
\hline Received Feb 04, 2019 & $\begin{array}{l}\text { amplifier for X-Band applications. The design and implementation are based } \\
\text { on HEMT transistors AFP02N2-00 of Alpha Industries }{ }^{\circledR} \text {. The matching }\end{array}$ \\
\hline Revised May 08, 2019 & circuit used for modeling the microwave amplifier is the quarter-wave \\
\hline Accepted Sept 30, 2019 & $\begin{array}{l}\text { transformers impedance matching technique associated to combline } \\
\text { bandpass filter. The proposed amplifier is implemented on a substrate of }\end{array}$ \\
\hline Keywords: & $\begin{array}{l}\text { epoxy FR } 4 \text { with a central frequency of } 1 \mathrm{GHz} \text { and a fractional bandwidth of } \\
0.18 \% \text { and is designed to be used in radar reception systems. The results }\end{array}$ \\
\hline Low noise amplifier & $\begin{array}{l}\text { show that the proposed LNA is unconditionally stable with a simulated gain } \\
\text { of } 20 \mathrm{~dB} \text { over the working frequency range of }[9.5-12.5] \mathrm{GHz} \text {. }\end{array}$ \\
\hline
\end{tabular}

Copyright $\odot$ 2019Institute of Advanced Engineering and Science. All rights reserved.

\footnotetext{
Corresponding Author:

Islam Toulali,

Equipe de Recherche en Smart Communications,

Mohammadia School of Engineers (EMI),

Mohammed Vth University, Rabat, Morocco

Email: islamtoulali@gmail.com
}

\section{INTRODUCTION}

Nowadays, the evolution of high data-rate communication systems and particularly the front-end receiver systems creates new challenges for circuit designers. Since both, the transmitter and receiver require high performance amplifiers and selective filters. In fact, microwave amplifiers with the characteristics of high gain, low noise, good input and output matching and compact size play an important role in modern wireless applications [1-2-3]. The main objective of our work consists of designing low noise and wideband amplifier that meets the requirements described above. Previous studies of researchers present different advantage. For example, detailed analysis of RF amplifiers has been presented by authors in [4-7]. Another related study of LNA was performed by [8] which divided the method of lumped input and output matching networks.

However, the most important factor while designing broadband microwave amplifiers is to amplify the signal without causing any significant distortion [9]. The specific purposes of this study, is developing a novel impedance matching technique, in order to solve the problems generally found in research papers. The amplifier is adapted by a microstrip combline filter connected to a single quarter wave transformer [10]. A step by step design implementation of the circuit is then presented. Combline filter is one of the most commonly used bandpass structures. The combline bandpass consists of mutually-coupled resonators which are physically less than a quarter wavelengths long and which are grounded at one end and capacitively loaded at the other end [11]. A conventional combline filter is shown in Figure 1. The contribution is a microstrip combline filter used as a matching network that can offers good selectivity and adaptation. The final circuit was simulated using ADS (Advanced Design System) software and implemented on FR4 epoxy substrate. 
The synthesis of combline bandpass filter is analyzed in Section II by using the mathematical expressions. The design methodology of amplifier based on the combline filter is then described. Simulations are presented in Section III to indicate the performance of the circuit. Finally, a conclusion is given in Section IV.

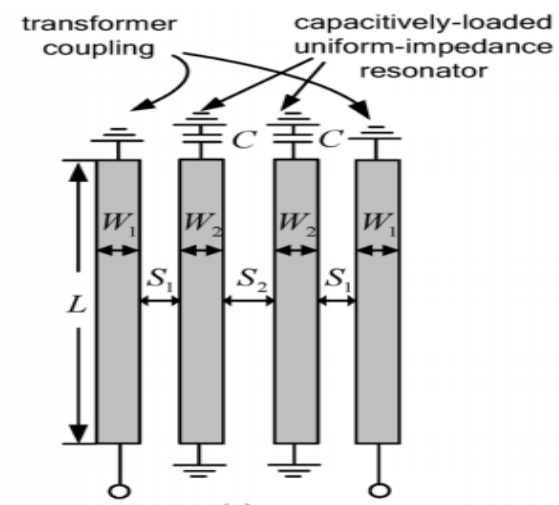

Figure 1. Compact planar structure

\section{RESEARCH METHOD}

\subsection{The matching network theory}

The matching circuit used for modeling the microwave amplifier is the combline band pass filter. Combline microwave filters are used extensively in mobile communication systems in recent years because of their compact size, low cost, wide tuning range and relatively low loss. In fact, band pass filters that are designed with combline cavity structure have several advantages [12]:

- Combline cavity filters are very compact.

- It is easier to realize high rejection for the stop bands.

- Combline filters are relatively easier to assemble ensuring faster production.

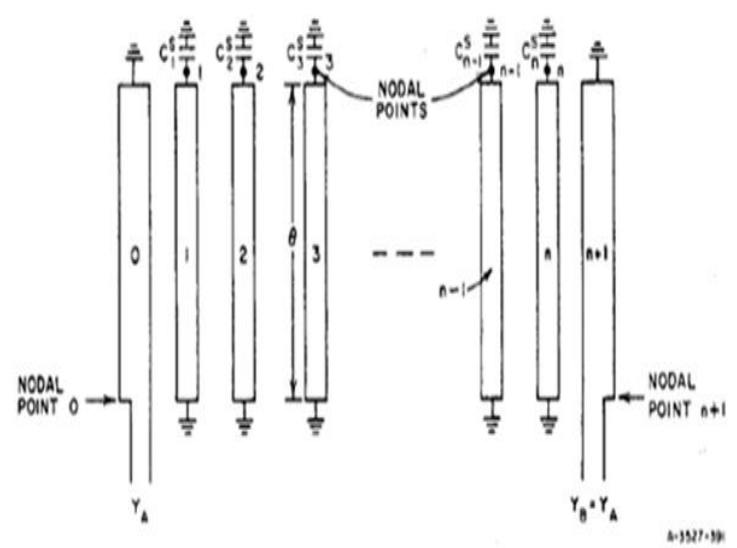

Figure 2. A combline, band pass filter [2]

Figure 2 represents a combline filter of $\mathrm{N}$ resonators in strip-line form. The resonators consist of line elements which are short-circuited at one end, with a lumped capacitance $\mathrm{C}_{\mathrm{f}}$ between the other end of each resonator line element and ground [13]. The resonators lengths are usually chosen to be between $20^{\circ}$ and $80^{\circ}$. Indeed when the value of the load capacity increases, the length of the line decreases, thus resulting in a more compact filter with a larger rejection band. The main advantage is an excellent stopband because the resonators are electrically short. The combline filter is compact, as the resonators may be significantly shorter than one quarter wavelength and are closer together than in an interdigital filter with the same bandwidth and ground plane spacing [14].

The design method of combline filter requires solving equations in order to obtain the important physical dimensions, namely the spacing, the width, the length of the resonators and the capacitance values. In this study, we provide an analysis of combline filters based on the method of graphs and a design method based 
on a bandpass prototype circuit [15]. The design procedures are indicated below; the first step is to suggest a low pass to band pass transformation for estimating the attenuation characteristics of combline filter [13] as indicated in (1), (2), (3):

$$
\frac{w \prime}{w_{1}^{\prime}}=\frac{2}{w}\left(\frac{w-w_{0}}{w_{0}}\right)
$$

With:

$$
w=\frac{w_{2}-w_{1}}{w_{0}}
$$

And

$$
w_{0}=\frac{w_{1}+w_{2}}{2}
$$

The design equations for combline filter are given by:

$$
\left.\frac{b_{j}}{Y_{A}}\right|_{j=1 \text { to } n}=\frac{Y_{\alpha j}}{Y_{A}}\left(\frac{\cot \theta_{0}+\theta_{0} \csc ^{2} \theta_{0}}{2}\right)
$$

Where $\theta_{0}$ is the electrical length of the resonator elements at the midband frequency $w_{0}$.

$$
\begin{aligned}
& \frac{G_{T 1}}{Y_{A}}=\frac{w \frac{b_{1}}{Y_{A}}}{g_{0} g_{1} w_{1}^{\prime}} \\
&\left.\frac{J_{j, j+1}}{Y_{A}}\right|_{j=1 \text { to } n-1}=\frac{w}{w_{1}^{\prime}} \sqrt{\frac{\left(b_{j} / Y_{A}\right)\left(b_{j+1} / Y_{A}\right)}{g_{j} g_{j+1}}} \\
& \frac{G_{T n}}{Y_{A}}=\frac{w \frac{b_{n}}{Y_{A}}}{g_{n} g_{n+1} w_{1}^{\prime}}
\end{aligned}
$$

Where $\mathrm{w}$ is the fractional bandwidth defined below and $\mathrm{g}_{\mathrm{i}}$ represents the element values of a lowpass prototype filter with a normalized cutoff frequency $\mathrm{w}_{1}^{\prime}=1 . \mathrm{Y}_{\mathrm{A}}$ is the characteristic admittance of the terminating lines.

The resonators consist of line elements that are short-circuited at one end, with a localized capacitance $C_{f}$ between the other end of each resonator line element and the ground. In Figure 2 lines 1 to $n$, along with their associated lumped capacitances $C_{1}^{s}$ to $C_{1}^{n}$ comprise resonators, while lines 0 and $n+1$ are not resonators but simply part of impedance transforming sections at the ends. The normalized capacitances per unit length between each line and ground are as follows [13]:

$$
\begin{gathered}
\frac{\mathrm{C}_{0}}{\varepsilon}=\frac{376.7 \mathrm{Y}_{\mathrm{A}}}{\sqrt{\varepsilon_{\mathrm{r}}}}\left(1-\sqrt{\frac{\mathrm{G}_{\mathrm{T} 1}}{\mathrm{Y}_{\mathrm{A}}}}\right) \\
\frac{\mathrm{C}_{1}}{\varepsilon}=\frac{376.7 \mathrm{Y}_{\mathrm{A}}}{\sqrt{\varepsilon_{\mathrm{r}}}}\left(\frac{\mathrm{Y}_{\alpha 1}}{\mathrm{Y}_{\mathrm{A}}}-1+\frac{\mathrm{G}_{\mathrm{T} 1}}{\mathrm{Y}_{\mathrm{A}}}-\frac{\mathrm{J}_{12}}{\mathrm{Y}_{\mathrm{A}}} \tan \theta_{0}\right)+\frac{\mathrm{C}_{0}}{\varepsilon} \\
\left.\frac{\mathrm{C}_{\mathrm{j}}}{\varepsilon}\right|_{\mathrm{j}=2 \text { to } \mathrm{n}-1}=\frac{376.7 \mathrm{Y}_{\mathrm{A}}}{\sqrt{\varepsilon_{\mathrm{r}}}}\left(\frac{\mathrm{Y}_{\alpha \mathrm{j}}}{\mathrm{Y}_{\mathrm{A}}}-\frac{\mathrm{J}_{\mathrm{j}-1, \mathrm{j}}}{\mathrm{Y}_{\mathrm{A}}} \tan \theta_{0}-\frac{\mathrm{J}_{\mathrm{j}, \mathrm{j}+1}}{\mathrm{Y}_{\mathrm{A}}} \tan \theta_{0}\right) \\
\frac{\mathrm{C}_{\mathrm{n}}}{\varepsilon}=\frac{376.7 \mathrm{Y}_{\mathrm{A}}}{\sqrt{\varepsilon_{\mathrm{r}}}}\left(\frac{\mathrm{Y}_{\alpha \mathrm{n}}}{\mathrm{Y}_{\mathrm{A}}}-1+\frac{\mathrm{G}_{\mathrm{Tn}}}{\mathrm{Y}_{\mathrm{A}}}-\frac{\mathrm{J}_{\mathrm{n}-1, \mathrm{n}}}{\mathrm{Y}_{\mathrm{A}}} \tan \theta_{0}\right)+\frac{\mathrm{C}_{\mathrm{n}+1}}{\varepsilon} \\
\frac{\mathrm{C}_{\mathrm{n}+1}}{\varepsilon}=\frac{376.7 \mathrm{Y}_{\mathrm{A}}}{\sqrt{\varepsilon_{\mathrm{r}}}}\left(1-\sqrt{\frac{\mathrm{G}_{\mathrm{n}}}{\mathrm{Y}_{\mathrm{A}}}}\right)
\end{gathered}
$$

Where $\varepsilon$ is the dielectric constant and $\varepsilon_{\mathrm{r}}$ is the relative dielectric constant of the medium of propagation. The normalized mutual capacitances $C_{j, j+1} / \varepsilon$ per unit length between adjacent line elements are:

$$
\begin{aligned}
& \frac{\mathrm{C}_{01}}{\varepsilon}=\frac{376.7 \mathrm{Y}_{\mathrm{A}}}{\sqrt{\varepsilon_{\mathrm{r}}}}-\frac{\mathrm{C}_{0}}{\varepsilon} \\
& \left.\frac{\mathrm{C}_{\mathrm{j}, \mathrm{j}+1}}{\varepsilon}\right|_{\mathrm{j}=1 \text { to } \mathrm{n}-1}=\frac{376.7 \mathrm{Y}_{\mathrm{A}}}{\sqrt{\varepsilon_{\mathrm{r}}}}\left(\frac{\mathrm{J}_{\mathrm{j}, \mathrm{j}+1}}{\mathrm{Y}_{\mathrm{A}}} \tan \theta_{0}\right)
\end{aligned}
$$




$$
\frac{\mathrm{C}_{\mathrm{n}, \mathrm{n}+1}}{\varepsilon}=\frac{376.7 \mathrm{Y}_{\mathrm{A}}}{\sqrt{\varepsilon_{\mathrm{r}}}}-\frac{\mathrm{C}_{\mathrm{n}+1}}{\varepsilon}
$$

The lumped capacitances $C_{j}^{s}$ are:

$$
\left.C_{j}^{s}\right|_{j=1 \text { to } n}=Y_{A}\left(\frac{Y_{\alpha j}}{Y_{A}}\right) \frac{\cot \theta_{0}}{w_{0}}
$$

It is usually desirable to make the capacitances $C_{j}^{s}$ in this type of filters sufficiently large that the resonator lines will be $\lambda_{0} / 8$ or less, long at resonance. After the normalized capacitances, $\mathrm{C}_{\mathrm{j}} / \varepsilon$ and $\mathrm{C}_{\mathrm{j}, \mathrm{j}+1} / \varepsilon$, have been computed, we use the charts of Figure 3 and Figure 4 and (17), (18) to determine the dimensions $w_{j}$ and $s_{j, j+1}$ of the lines for specified $t$ and $b[13]$. Figure 3 can be used to determine $s_{j, j+1} / b$, then $s_{j, j+1}$ is obtained.

The cross-sectional dimensions of the bars and spacings between them are determined as follows [13]:

$$
\frac{(\Delta \mathrm{C})_{\mathrm{k}, \mathrm{k}+1}}{\varepsilon}=\frac{\mathrm{C}_{\mathrm{k}, \mathrm{k}+1}}{\varepsilon}
$$

And the normalized width of the kth bar is:

$$
\frac{w_{k}}{b}=\frac{1}{2}\left(1-\frac{t}{b}\right)\left[\frac{1}{2}\left(\frac{C_{k}}{\varepsilon}\right)-\frac{\left(C_{f e}^{\prime}\right)_{k-1, k}}{\varepsilon}-\frac{\left(C_{f e}^{\prime}\right)_{k, k+1}}{\varepsilon}\right]
$$

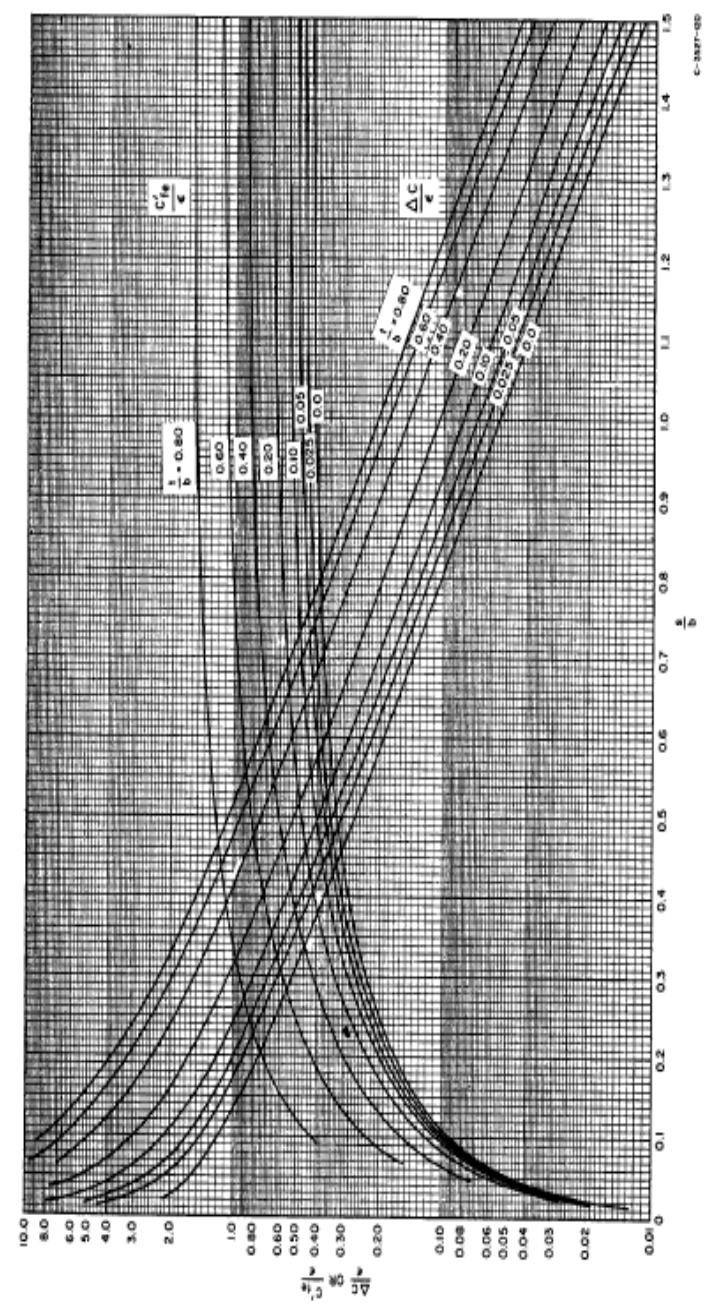

Figure 3. Normalized even-mode fringing capacitance $C_{f e}^{\prime} / \varepsilon$ and interbar capacitance $\Delta C / \varepsilon$ for coupled rectangular bars [13] 


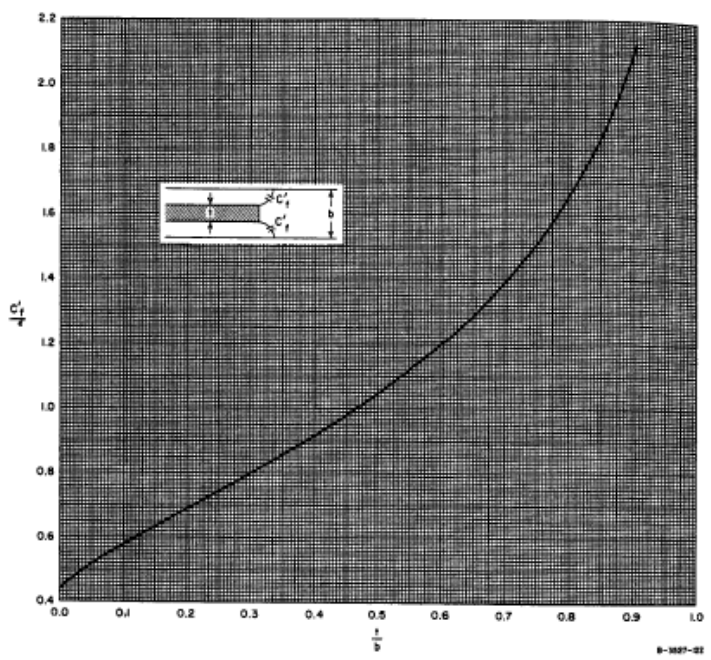

Figure 4. Normalized fringing capacitance for an isolated rectangular bar [13]

\subsection{Fiter design process}

A stripline [16] combline band pass filter was designed to have fractional bandwidth of $27 \%$ or $\mathrm{FBW}=0.27$ at the midband frequency of $11 \mathrm{GHz}$. Tschebyshev low pass prototype filter of order $\mathrm{n}=3$ with pass band ripple of $0.1 \mathrm{~dB}$ was chosen. The low pass prototype parameters given for a normalized low pass cutoff frequency $\Omega \mathrm{c}=1$ are: $\mathrm{g}_{0}=\mathrm{g}_{4}=1, \mathrm{~g}_{1}=\mathrm{g}_{3}=1.0315$ and $\mathrm{g}_{2}=1.1474$.

The band pass filter topology is shown in Figure 5 and analyzed using the ADS software of Agilent Technologies relying on the S-parameters. A dielectric substrate [16] with a relative dielectric constant of 4.32 and a thickness of $1.6 \mathrm{~mm}$ was chosen for the filter design. The dimensions $\mathrm{w}_{[j]}$ and $\mathrm{s}_{[j]}$ of the lines and capacitances $C_{j}$ between each line and ground are represented.

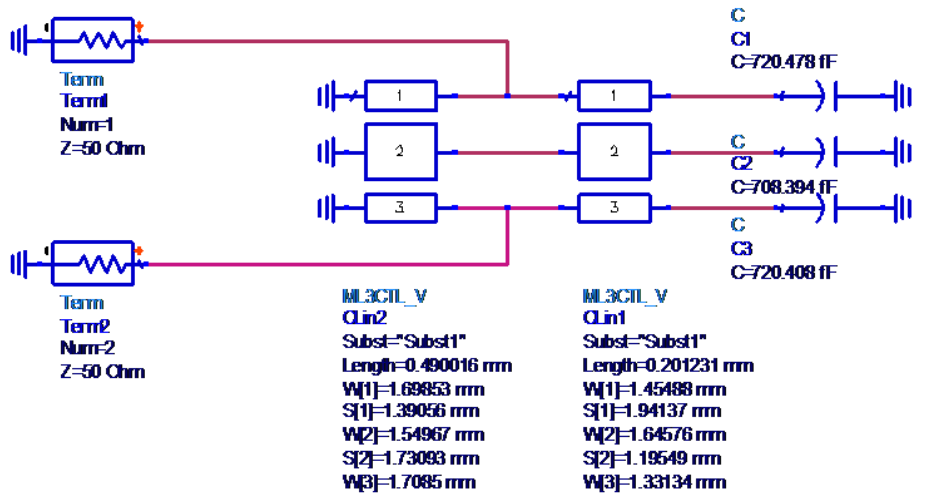

Figure 5. Structure of the third-resonator combline filter

The simulated results of the designed filter are satisfying; the filter is capable of passing the frequencies between range $[9.5-12.5] \mathrm{GHz}$ with minimum loss as it is described on Figure 6 .

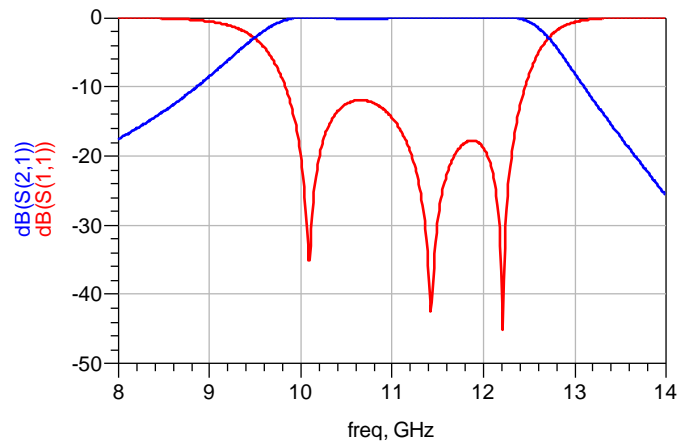

Figure 6. Structure of the third-resonator combline filter 


\section{CIRCUIT ANALYSIS AND INTERPRETATIONS}

Based on the matching circuit explained in the previous section, the broadband low noise amplifier was modeled as indicated in Figure 7. The proposed LNA comprises two transistors separated by a transmission line, and a matching networks [17] which are located in the input and output.

We adopted the HEMT transistors AFP02N2-00 of Alpha Industries ${ }^{\circledR}$, the block of impedance transformation was used to adapt the impedance at $11 \mathrm{GHz}$. This transmission line can eliminate the imaginary part of the impedance to adapt. After that a second transmission line designed by a single quarter wave transformer was used to approach the center of the Smith chart. Finally, we integrated the thirdresonator combline filter at the input and the output of the circuit.

We have simulated the two stages LNA constituted by the physical parameters of each block and implemented on FR4 epoxy substrate using ADS (Advanced Design System) software. Tuning and optimization tools of ADS software have been used to optimize results.

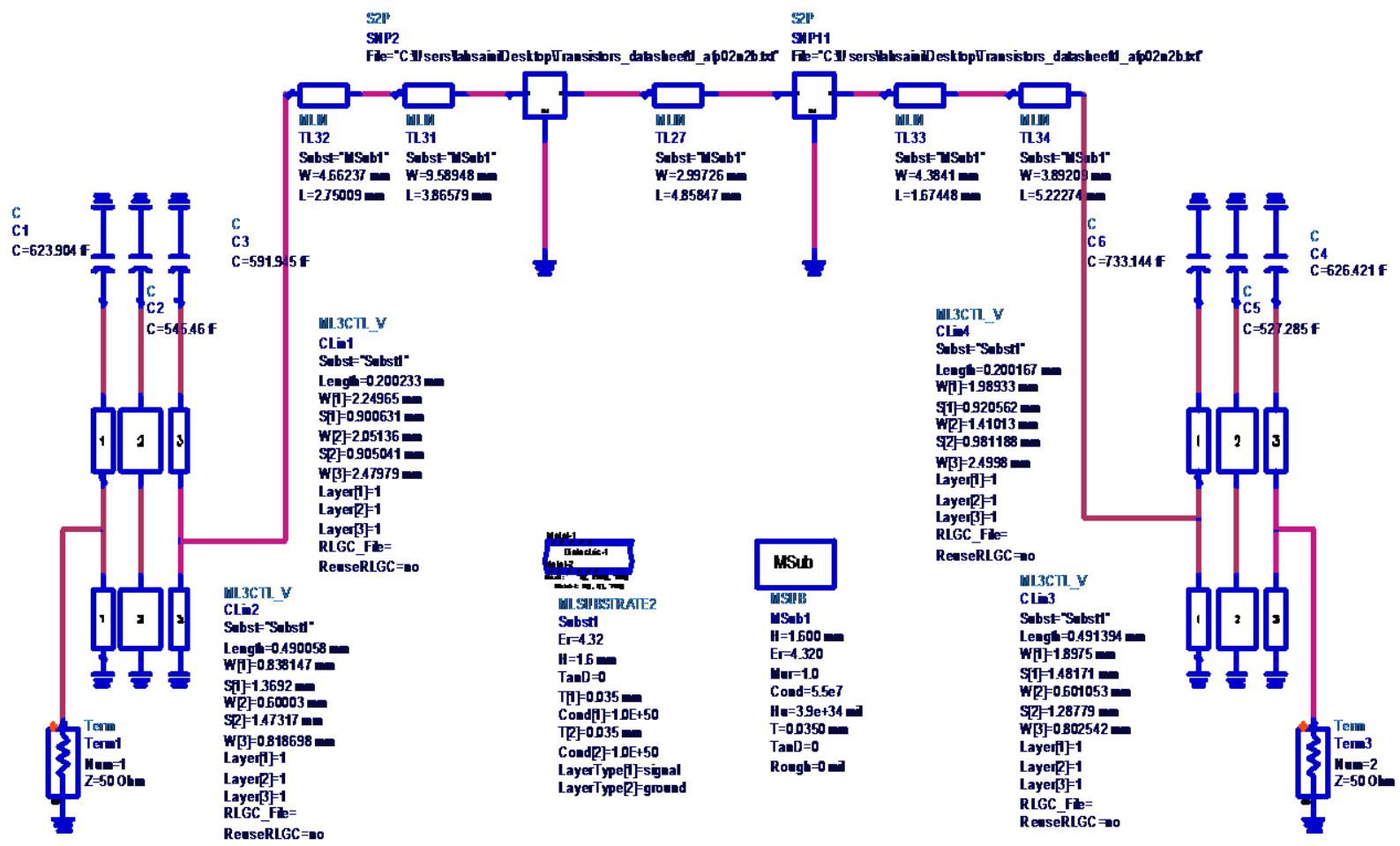

Figure 7. Scheme of the modeled amplifier

Figure 8 illustrates the simulated results of gain $S_{21}$ and reverse transmission coefficient which is given by $\mathrm{S}_{12}$. The gain is about $20.5 \mathrm{~dB}$ from $9.5 \mathrm{GHz}$ to $12.5 \mathrm{GHz}$ and $\mathrm{S}_{12}$ is less than $-35 \mathrm{~dB}$ over the band of interest.

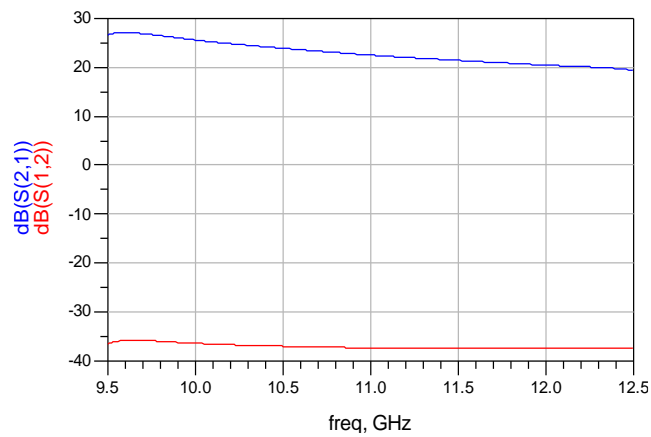

Figure 8. Transmission Parameters

The simulated results of input and output reflection coefficients are shown in Figure 9. The input reflection coefficient is less than $-23 \mathrm{~dB}$ and the output reflection coefficient is widely inferior to $-25 \mathrm{~dB}$. 


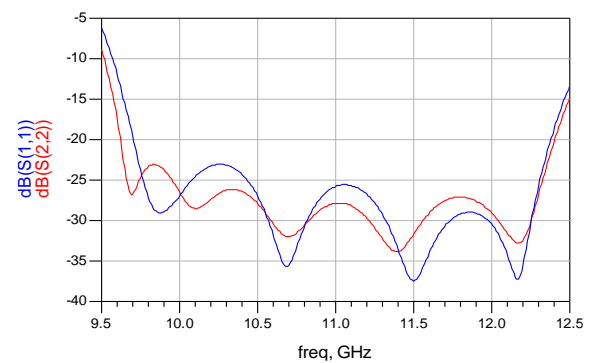

Figure 9. Reflection Parameters

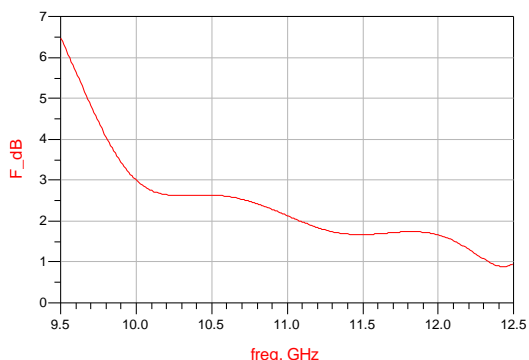

Figure 10. Noise figure

The noise factor is the degradation of signal to noise ratio (SNR). The noise figure obtained is around $2.2 \mathrm{~dB}$ at $11 \mathrm{GHz}$ as shown in Figure 10. The designed amplifier is unconditionally stable; the stability coefficients (Mul and MuPrime1) are greater than 1 as indicated in Figure 11.

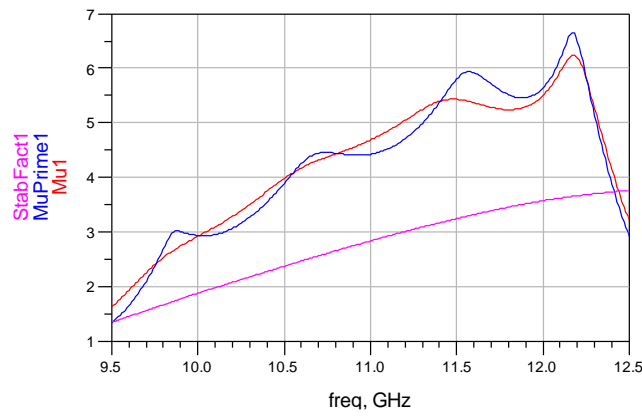

Figure 11. Stability coefficients

Table 1 presents a comparison of the results with those of other researchers. Our proposed amplifier presents suitable simulations results compared with other design techniques [18-21].

Table 1. Summary of the LNA performances

\begin{tabular}{ccllllcc}
\hline \hline & $\begin{array}{c}\text { Frequency } \\
(\mathrm{GHz})\end{array}$ & $\mathrm{S}_{11}(\mathrm{~dB})$ & $\mathrm{S}_{21}(\mathrm{~dB})$ & $\mathrm{S}_{22}(\mathrm{~dB})$ & $\mathrm{S}_{12}(\mathrm{~dB})$ & Bandwidth (GHz) & Technology \\
\hline This work & {$[\mathbf{9 . 5 - 1 2 . 5}]$} & $<-\mathbf{- 2 3}$ & $\mathbf{> 2 0 . 5}$ & $<-\mathbf{- 2 5}$ & $<-\mathbf{3 5}$ & 3 GHz & HEMT \\
{$[18]$} & {$[7-12]$} & $<-9$ & $>12$ & $<-15.12$ & - & Narrow band & FET \\
{$[19]$} & {$[8-12]$} & $<-10$ & $>15$ & $<-10$ & - & $1.5 \mathrm{GHz}$ & CMOS \\
{$[20]$} & {$[10-12]$} & $<-18.9$ & $>20.37$ & $<-19.10$ & $<-36.29$ & $2 \mathrm{GHz}$ & HEMT \\
{$[21]$} & {$[10-12]$} & $<-32$ & $>20$ & $<-40$ & $<-35$ & $2 \mathrm{GHz}$ & HEMT \\
\hline
\end{tabular}

\section{CONCLUSION}

In this paper, an appropriate approach for designing low noise amplifier using the concepts of quarter wave transformers and combline filter has been proposed. The fast and accurate tools of ADS based on optimization, allows obtaining directly optimal parameters of combline band pass filter. Thus, the amplifier was configured and the simulated results achieve high performance features. As a prospect of development of research, we will analyze a new component of the communication block which is the comparator as proposed in [22].

\section{REFERENCES}

[1] D. Françcois and R. Olivier (11 June, 2008). Electronique Appliquée aux Hautes Fréquences: Principes et Applications (2ed.). Paris: Dunod.

[2] D. M. Pozar,(2005). Microwave Engineering (3 ed.). New York: John-Wiley \& Sons.

[3] C. Fűzy, A. Zólomy, "Design of Broadband Complex Impedance-Matching Networks and their Applications for Broadbanding Microwave Amplifiers", 18-th International conference on microwaves, radar and wireless communications, 14-16 June 2010.

[4] K. G. Sawarkar, R. V. Navagare and K. Tuckley, "Bandwidth Enhancement of Low Noise Amplifier Using Inductive Source and Distributed Components," (2016), IEEE International Conference on Recent Trends in Electronics, Information \& Communication Technology (RTEICT), Bangalore, 2016, pp. 1461-1465.

[5] A. K. Ray and R. C. Shit, "Design of Ultra-Low Noise, Wideband Low-Noise Amplifier for Highly Survival Radar Receiver," in IET Circuits, Devices \& Systems, vol. 10, pp. 473-480, 2016. 
[6] F. Oktafiani,et al., "Measurement and Evaluation of Tx/Rx Antennas for X-Band Radar System", (2016) Telecommunication Computing Electronics and Control (TELKOMNIKA), vol. 14, no. 2, pp. 555-562.

[7] I. I. Shiva Ghandi, Z. Yusoff JahariahSampe, "0.5 GHz $-1.5 \mathrm{GHz}$ Bandwidth $10 \mathrm{~W}$ GaN HEMT RF Power Amplifier Design" (June 2018) International Journal of Electrical and Computer Engineering (IJECE), 9(1), pp. 221-230

[8] G. S. Kishor, K. Tuckley, "Negative image amplifier technique for performance enhancement of ultra wideband LNA," (February 2019), International Journal of Electrical and Computer Engineering (IJECE), 8(3), pp. 18371843.

[9] H. Bogucka, A. Kliks, P. Kryszkiewicz. (August 2017). Advanced Multicarrier Technologies for Future Radio Communication: $5 G$ and Beyond. Wiley

[10] R. E. Collin. (January 5, 2001). "Foundations for Microwave Engineering" (2nd edition). Wiley-IEEE Press.

[11] R. W. Rhea, (1994). "HF filter design and computer simulation. Noble Publishing Corporation".

[12] N. Dhanasekharan, "A Practical Design of Lumped, Semi Lumped and Microwave Cavity Filters", Springer-Verlag Berlin Heidelberg (2013).

[13] G.L. Matthaei, L. Young and E.M.T. Jones, Microwave Filters, Impedance-Matching Networks and Coupling Structures, 1st ed., Artech House, Massachusetts, 1980.

[14] Ian Hunter, "Theory and Design of Microwave Filters", the Institution of Engineering and Technology, London, United Kingdom (2016).

[15] P. Jarry, J. Beneat, (2008) “Advanced design techniques and realizations of microwave and RF filters”, Wiley-IEEE Press.

[16] V.R.K. Murthy, S. Sundaram, B. Viswanathan (1994). "Microwave Materials"; Springer-Verlag Berlin Heidelberg New York.

[17] G. Gonzalez, (August 30, 1996). "Microwave transistor amplifiers, Analysis and Design (2nd edition)". Prentice Hall.

[18] K.E.C.Lessi, “An X-Band Low Noise Amplifier Design for Marine Navigation Radars", International Journal of Communications, Network and System Sciences, vol. 7, no. 3, pp. 75-82, 2014.

[19] J.-H. Y. ,. H.-H. Y. ,. a. L.-C. S. Cheng-Chi Yu, "A Broadband Low Noise Amplifier for X-band Applications," Progress In Electromagnetics Research Symposium Proceedings, pp. 541-543, 2011.

[20] M. Lahsaini, L. Zenkouar, "Interdigital Filters for Broadband Impedance Matching of Microwave Amplifiers," (2015) International Journal on Communications Antenna and Propagation (IRECAP), 5 (1), pp. 21-27.

[21] I. Toulali, M. Lahsaini, L. Zenkouar, "Design of a low noise amplifier using the quarter wave transformers matching technique in the frequency band [9-13] GHz," (2015) International Journal on Communications Antenna and Propagation (IRECAP), 5 (4), pp. 248-255.

[22] F. R. Labonnah, B. I. Mamun, I. R. Wan, M. Mohammad, M. S. Lariyah, "Design and Analysis of High Gain Low Power CMOS Comparator," (2018) Indonesian Journal of Electrical Engineering and Informatics (IJEEI), 6 (4), pp. 471-476.

\section{BIOGRAPHY OF AUTHORS}
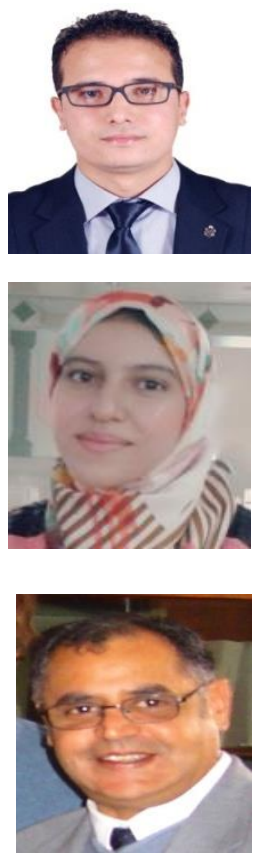

Mohammed Lahsaini was born in Sidi Slimane, Morocco, in 1984. He received the Master's degree in Telecommunication and Microwave Devices from National School of Applied Sciences, Fes, Morocco, in 2011 and Doctoral degree from Mohammadia School of Engineers, Mohammed V University, Agdal, Rabat, Morocco. He is currently a professor at the faculty of Science, Moulay Ismail University, Meknes, Morocco. His research interests include Microwave Circuits, Transmission and Reception Systems.

Islam Toulali was born in Rabat, Morocco, in 1990. She studied mathematics and physics at Ibn Ghazi Higher School Preparatory Classes in Rabat, Morocco. And obtained the engineer degree in telecommunications and networks from National School of Applied Sciences in 2014, Oujda, Morocco. She is preparing her PhD in Mohammadia School of Engineers, Mohammed V University, Agdal, Rabat, Morocco. Her research interests include Microwave Circuits and Systems.

Lahbib Zenkouar was born in Meknes, Morocco. He received the Doctoral degree in CAD-VLSI from University of Sciences and Techniques of Languedoc, Montpellier, France and Ph.D. Sciences and Techniques in Telecommunication from Institute of Electricity of Montefiore, Liege, Belgium, $\mathrm{He}$ is currently Leader of research team TCR of the Laboratory Electronic and Communication -LEC- and Professor at Electrical Engineering Department, Mohammadia School of Engineers, Mohammed V University, Agdal, Rabat, Morocco. His research interests focuses on the design of Microwave Circuits and Systems and Information Technology. 